\title{
Role of Active Principles of Podophyllum hexandrum in Amelioration of Radiation Mediated Lung Injuries by Reactive Oxygen/Nitrogen Species Reduction
}

\author{
Rashmi Saini, Savita Verma, Abhinav Singh, Manju Lata Gupta* \\ Institute of Nuclear Medicine and Allied Sciences (INMAS), Defence Research and \\ Development Organization (DRDO), New Delhi, India \\ Email: *drmanjugupta2003@yahoo.com
}

Received November 30, 2012; revised December 28, 2012; accepted January 11, 2013

Copyright (C) 2013 Rashmi Saini et al. This is an open access article distributed under the Creative Commons Attribution License, which permits unrestricted use, distribution, and reproduction in any medium, provided the original work is properly cited.

\begin{abstract}
Radiation induced reactive oxygen/nitrogen species (ROS/RNS) are reported to cause lung injuries such as pneumonitis and fibrosis which may be fatal at times. Current study is designed to analyse the radioprotective efficacy of $P$. hexandrum active principles (G-002M) on lungs of mice exposed to high dose of gamma irradiation (7 Gy). Cellular profiles and inflammatory cell infiltrates of irradiated bronchoalveolar lavage fluid (BALF) have shown correlations with lung pathology. Cell counts were determined in BALF of control, 7 Gy radiation exposed and radiation with G-002M pretreated mice. ROS/Nitric Oxide (NO) production was measured by 2,7 dichlorodihydrofluorescein diacetate (DCF-DA) and diaminofluorescein diacetate (DAF-2DA) through microscopy and flow cytometry respectively. Immunostaining of inducible nitric oxide synthase (iNOS) in BALF cells and lung sections was also observed microscopically. iNOS expression was observed in lungs by western blotting. BALF was also processed to estimate total protein, LDH, and phospholipids content. Catalase, reduced Glutathione (GSH), Glutathione reductase (GR) and lipid peroxidation were estimated in lung tissues. Pre-administration of G-002M significantly decreased radiation mediated neutrophils count in BALF of irradiated mice. ROS generation, iNOS expression, total protein, LDH and phospholipids were found less affected in G-002M pretreated group in comparison to radiation alone group. Radiation exposure to mice was found apparently leading to parenchymal fibrosis, an architectural distortion of the lung tissue with edema, infiltration of inflammatory blood cells with increased immunolabeling of iNOS. G-002M pretreatment significantly countered radiation mediated increased lipid peroxidation and decreased GR, catalase and GSH in mice. Current study demonstrates possible role of $P$. hexandrum $(\mathrm{G}-002 \mathrm{M})$ in minimizing lung damage induced by radiation mediated ROS/RNS generation.
\end{abstract}

Keywords: Bronchoalveolar Lavage Fluid; Lung Injury; Reactive Nitrogen Species; Podophyllum hexandrum; Radiation

\section{Introduction}

Radiation inflicts various histopathological changes in the lung that can be diversed with overlapping features, characterized by varying degrees of inflammation and fibrosis $[1,2]$. Architectural distortion of the lung tissue along with thickening of alveolar wall (edema), increased degree of vascular congestion, hyaline membrane formation in distal airway and inflammatory cell accumulation are found to be common in pulmonary disease cases. Under pathological conditions, including pulmonary fibrosis, the production of reactive oxygen species (ROS)

"Corresponding author. is augmented by a variety of mechanisms, resulting into hydroxyl radicals and reactive nitrogen species (RNS) generation [3]. Lungs like other tissues have highly specialized and compartmentalized antioxidant defence mechanisms to protect against ROS and RNS. Several studies have demonstrated that nitric oxide (NO) is a significant mediator of radiation-induced acute lung injury [3-6]. Inhibition in inducible nitric oxide synthase (iNOS) isoform expression, enhanced in the irradiated lungs, can decrease NO production mediated lung damage [7]. Production of NO, being a small and diffusible signalling molecule, is tightly regulated and is produced at the right time, in right amount and at right place [8]. 
Thus, the localization of the ROS/RNS generation and the concentration of protective antioxidants play the lead role in expression of radiation inflicted lung injuries and mediating in pathologic response. Lung inflammation, as manifested by infiltration of large numbers of neutrophils, eosinophils, macrophages, and lymphocytes into the lung, can be monitored by examining presence of inflammatory cells in bronchoalveolar lavage fluid (BALF) and/or histologically prepared lung tissue sections. Measurement of inflammatory cell infiltrates of BALF has been shown to correlate with disease severity [9-12]. Cellular differential profiles in BALF are used to determine the nature of the disease and their appearance in the interstitium of lungs may have diagnostic or therapeutic impact [13-17]. Several interstitial lung disorders can be characterized by evaluating the distribution of cell types and their subpopulations in BALF $[10,18,19]$. BALF study is well reported tool in the sampling of the lower respiratory tract both for clinical indications and for research related investigations [9]. Quantitation of the cell types recovered from BALF is also among vital parameters for evaluation of the biological effect of ionizing radiation in lungs.

Increased threat of nuclear or radiological exposures by the multifaceted use of radiation has expressed the need for development of safe and effective radioprotector. Undesired toxicity of synthetic radioprotectors and their analogues have precluded them from clinical use and necessitated the search for safe alternative agents. Among the high altitude plants screened for radioprotective efficacy, Podophyllum hexandrum (Division: Magnoliophyta; Family: Berberidaceae) has been found to be a potent scavenger of free radicals induced by ionizing radiation [20-24]. The present study has focused on the radioprotective potential of G-002M (formulation prepared by combination of three active compounds isolated from $P$. hexandrum) on ROS/RNS mediated lung tissue damages.

The current study has been specifically designed to evaluate the modulatory effect of formulation of $\mathrm{P}$. hexandrum (G-002M) on 1) cellularity and differential cell counts in BALF; 2) ROS/NO production; 3) expression of iNOS and 4) alterations in antioxidant enzymes(GSH, GR catalase) and lipid peroxidation following radiation inflicted lung injury.

\section{Materials \& Methods}

\subsection{Reagents and Antibodies}

Goat anti-rabbit HRP (Cat No. Sc-2030) was procured from Santa Cruz (CA). Polyclonal antibodies to iNOS (Cat No.-N7782), Goat anti rabbit FITC 488 (Cat No. F4018), 2,7 dichlorodihydrofluorescein diacetate (DCFDA), diaminofluorescein diacetate (DAF-2DA) and all other required chemicals were obtained from Sigma Aldrich Co. (St Louis, MO).

\subsection{Preparation of G-002M}

The drug (G-002M) was prepared by combining three compounds isolated from dried rhizomes of $\mathrm{P}$. hexandrum plant, collected from high altitude region of Leh and Ladakh, India. The dried rhizomes were crushed to get fine powder which was processed further using standard protocols. The three active principles isolated after elaborate processing, were analysed on HPLC for their chemical identification and purity. The active principles were identified as podophyllotoxin, podophyllotoxin- $\beta$ D-glucoside and rutin. All three molecules were in their $>97 \%$ purity. G-002M was prepared freshly at the time of administration by dissolving in DMSO which was diluted further in distilled water to the final concentration of 1:9 (DMSO: distilled water). The injectable volume was $200 \mu 1 /$ mice administered intramuscularly one hour before irradiation of animals.

\subsection{Animals and $\boldsymbol{\gamma}$-Ray Irradiation}

Strain "A" female mice (25 - 28 g), 8 - 10 weeks old were obtained from the institute animal house. All the experiments were based on institutional ethical guidelines. Mice were exposed to a single dose of $7.0 \mathrm{~Gy}$ in ${ }^{60} \mathrm{CO}$ gamma chamber (Cobalt Teletherapy Bhabhatron-II) at the dose rate of $0.925-0.828 \mathrm{cGy} / \mathrm{sec}$. Radiation dose calibration was done by Fricke's dosimetry method by radiation physicists. All the experiments were repeated thrice.

\subsection{Experimental Design}

As per previous reports $[3,25,26]$, the detailed studies in mice BALF were performed after 2 weeks of irradiation as acute lung damage peaked at week 2. Animals were divided into four experimental groups: 1) control; 2) irradiated; 3) G-002M plus radiation; 4) G-002M only. In irradiated group, the mice were exposed to $7 \mathrm{~Gy}$ (whole body). G-002M plus radiation group, was administered with G-002M intramuscularly prior to irradiation $(-1 \mathrm{hr})$. G-002M was dissolved freshly in DMSO and diluted with water maintaining the final concentration of DMSO to $10 \%$ of total injectable $(200 \mu \mathrm{l} / \mathrm{mice})$.

\subsection{Collection of BALF and Its Cells Count}

Mice were sacrificed and lungs were lavaged 5 times with $200 \mu \mathrm{l}$ of buffered saline at $37^{\circ} \mathrm{C}$ [27]. Cells were collected individually from three animals, after centrifugation $\left(2000 \mathrm{rpm}\right.$ for $10 \mathrm{~min}$ at $\left.4^{\circ} \mathrm{C}\right)$ were processed for cytological evaluation. BALF cells were quantified with a haemocytometer by the conventional method and also by fully automated 5 part Hematology Analyzer (ADVIA 2120 Seimens Diagnostics, USA). Data from the Perox and Baso channels were used to determine BALF total 
WBC count and differential analysis [28]. Differential cell counts (lymphocytes, neutrophils) were calculated from the percentage of each cell type taken from a count of at least 200 cells on a stained preparation of BALF. Fluid from the lavage was used for evaluation of biochemical changes after cell removal.

\subsection{BALF Smear}

BALF smears were prepared for microscopic examination [29]. Briefly, the aspirated cells from lavage fluid were collected and centrifuged at $2000 \mathrm{rpm}$ for $10 \mathrm{~min}$. The supernatant was discarded, cells mixed with fetal bovine serum and smeared on clean glass slide. Slides were air-dried, stained with May-Grünwald Giemsa stain for $10 \mathrm{~min}$ and total 200 different cell types (neutrophils and lymphocytes) were counted to determine percentage of differential cell counts in BALF.

\subsection{ROS/NO Measurement in BALF Cells by Flow Cytometry}

BALF cells $\left(2 \times 10^{4} / \mathrm{ml}\right)$ were washed with PBS $(137$ $\mathrm{mM} \mathrm{NaCl}, 27 \mathrm{mM} \mathrm{KCl}, 32 \mathrm{mM} \mathrm{Na} \mathrm{HPO}_{4}, 15 \mathrm{mM}$ $\mathrm{K}_{2} \mathrm{HPO}_{4}, 15 \mathrm{mM} \mathrm{KH} \mathrm{PO}_{4}, \mathrm{pH}$ 7.4) and incubated for 30 min with DCF-DA $(10 \mu \mathrm{m})$ and DAF-2DA $(10 \mu \mathrm{m})$ dye for estimating ROS generation and NO production respectively $[8,30]$. Real time ROS generation and NO production was measured by acquiring 10,000 cells from each sample in flow cytometer and analyzed by the Cell Quest program.

\subsection{DCF-DA and DAF-2DA Fluorescence Intensity Measurement in BALF Cells}

BALF cells $\left(2 \times 10^{4} / \mathrm{ml}\right)$ were washed with PBS, and incubated for 15 min with DCF-DA $(10 \mu \mathrm{m})$ dye. DCF-DA loaded cells were dispensed on $0.01 \%(\mathrm{w} / \mathrm{v})$ poly-L-lysine coated coverslips and monitored for real time ROS generation under fluorescence microscope (Olympus, Model DP 72). For estimation of NO production, BALF cells $\left(2 \times 10^{4} / \mathrm{ml}\right)$ were incubated for $15 \mathrm{~min}$ with DAF-2DA $(10 \mu \mathrm{m})$ dye, dispensed on $0.01 \%(\mathrm{w} / \mathrm{v})$ polyL-lysine coated coverslips and monitored for real time NO production under fluorescence microscope. Data was captured with Image-Pro Plus Software 7.0, and photographs were processed using Adobe Photoshop software San Jose, CA. Cells without dyes or fixed cells (1 hr with $4 \%$ paraformaldehyde), incubated with dyes were used as negative controls.

\subsection{BALF Cells Studies Using Immunocytochemistry}

BALF cells $\left(2 \times 10^{4}\right.$ cells $\left./ \mathrm{ml}\right)$ were fixed overnight at $25^{\circ} \mathrm{C}$ in $4 \%(\mathrm{w} / \mathrm{v})$ paraformaldehyde in PBS ( $\left.\mathrm{pH} 7.4\right)$ and washed two times for $5 \mathrm{~min}$ each with PBS containing
$0.5 \%(\mathrm{w} / \mathrm{v})$ glycine. The washed cells were allowed to adhere on $0.01 \%(\mathrm{w} / \mathrm{v})$ poly-L-lysine coated coverslips, permeabilized with $0.2 \%$ (v/v) Triton X-100 (5 - $10 \mathrm{~min})$ and blocked with $1 \%$ BSA for 2 hrs. Cells were incubated overnight at $4^{\circ} \mathrm{C}$ with antibodies against iNOS at a dilution of $1: 100$ and were subsequently stained at $4^{\circ} \mathrm{C}$ for $4 \mathrm{~h}$ with FITC tagged secondary antibody (1:500). Nuclei were stained with DAPI $(0.5 \mu \mathrm{g} / \mathrm{ml})$ at $25^{\circ} \mathrm{C}$ for 15 min. Control samples were separately processed by omitting primary antibodies. Mounted coverslip images were acquired by fluorescence microscope and were presented using Adobe Photoshop software.

\subsection{Histological Studies in Lung Tissues}

Anesthesized mice were dissected and lungs tissues were excised. After removing the blood clots, lung tissues were fixed in $10 \%$ buffered formalin. Samples were processed using standard histological procedures. 3 - 5 $\mu \mathrm{m}$ sections were cut from lung tissues embedded in paraffin by using semi automated microtome. Sections were stained with hematoxylin-eosin (H-E) and evaluated under the light microscope.

\subsection{Immunohistochemistry of Lungs Sections}

Excised tissues were fixed in $10 \%$ buffered formalin and embedded in paraffin. $5 \mu \mathrm{m}$ sections were deparaffinised, rehydrated, rinsed in distilled water and washed in Tris buffer saline. The slides were immersed in citrate buffer ( $\mathrm{pH}$ 6.0) and antigen retrieval was done using a domestic microwave oven at 600 wattage. Immunohistochemistry was then performed as described previously [31]. In brief, lung tissue sections were adhered on coverslips, deparaffinised and incubated with primary antibody (iNOS, 1:200 dilution) overnight at $4^{\circ} \mathrm{C}$ and secondary antibody tagged with FITC (1:500 dilution) for $4 \mathrm{hrs}$ at $4^{\circ} \mathrm{C}$. Slides were stained with DAPI $(0.5 \mathrm{mg} / \mathrm{ml})$ and sections were visualized under fluorescence microscope.

\subsection{Assessment of iNOS Expression by Western Blotting}

Frozen lung tissue was homogenized in RIPA buffer (50 $\mathrm{mM}$ Tris-HCl, $\mathrm{pH} 7.4,150 \mathrm{mM} \mathrm{NaCl}, 1 \mathrm{mM}$ EDTA, $0.1 \%$ SDS, $0.5 \%$ Sodium deoxycholate, $1 \%$ Nonidet-P40, and a mixture of protease inhibitors), and protein concentration was determined using the Bradford Assay. Protein $(50 \mu \mathrm{g})$ was solubilized in SDS sample buffer, separated on $10 \%$ SDS-PAGE and transferred onto a nitrocellulose membrane at $120 \mathrm{~V}$ for $1 \mathrm{~h}$, by the method of Saini et al, with modifications [8]. The membrane was stained with Ponceau S stain to check the efficiency of transfer of proteins and blocked with 5\% skimmed milk in PBST, $10 \mathrm{mM}$ Tris-HCl, $\mathrm{pH} 7.5,150 \mathrm{mM} \mathrm{NaCl}$ 
containing $0.1 \%$ Tween 20 . The membrane was then incubated with anti-iNOS antibody (1:1000) overnight at $4^{\circ} \mathrm{C}$. The membrane was washed three times ( 5 min each) with blocking buffer and then incubated with HRPconjugated anti-rabbit IgG (1:5000) for 2 hrs. After being washed three times ( 5 min each), the blot was developed with ECL reagents and exposed to X-ray film to visualize the protein bands.

\subsection{Measurement of Total Protein Concentration and LDH Activity in BALF}

Determination of LDH activity in BALF was done according to the method of Seth et al., 1994 [32]. Briefly, the samples were incubated with sodium pyruvate and the reaction was initiated by nicotinamide adenine dinucleotide (NADH). Absorbance was recorded at $340 \mathrm{~nm}$ at the difference of $15 \mathrm{secs}$ for $1 \mathrm{~min}$. Protein contents were measured by Bradford, 1976 method [33]. Standard curve was plotted by using different concentrations of bovine serum albumin (BSA).

\subsection{Phospholipids Content in BALF}

Phospholipids content was measured with Dithiocynatoiron method [34]. Briefly, 0.2 ml BALF was heated for $5 \mathrm{~min}$ at $60^{\circ} \mathrm{C}$. After addition of $0.5 \mathrm{ml}$ thiocynatoiron reagent and $0.3 \mathrm{ml}$ of $0.17 \mathrm{~N}$ hydrochloric acid, the mixture was incubated for $5 \mathrm{~min}$ at $35^{\circ} \mathrm{C}$. The thiocynatoiron-phospholipid complex formed was extracted with 1.5 $\mathrm{ml} \mathrm{1,} \mathrm{2-dichloroethane} \mathrm{by} \mathrm{vigorous} \mathrm{shaking} \mathrm{for} 2 \mathrm{~min}$. After centrifugation, the absorbance of the lower layer containing thiocynatoiron-phospholipid complex was measured at $470 \mathrm{~nm}$ against a blank without BALF. Absorbance of thiocynatoiron-phospholipid complex is directly proportional to phopholipids content in the sample.

\subsection{Biochemical Estimations in Lung Homogenate}

\subsubsection{Lipid Peroxidation Estimation}

Lipid peroxidation (LPX) level was estimated as nmoles of malondialdehyde (MDA) formed, by the method of Buege and Aust, 1978 [35]. In brief, reaction mixture containing lung tissue homogenate, $15 \% \quad \mathrm{w} / \mathrm{v}$ trichloroacetic acid (TCA) and $0.37 \% \mathrm{w} / \mathrm{v}$ tribarbituric acid (TBA) was boiled at $95^{\circ} \mathrm{C}(30 \mathrm{~min})$, centrifuged at 8000 $\mathrm{g}$ for $10 \mathrm{~min}$ and absorbance of the supernatants was recorded at $535 \mathrm{~nm}$. The concentration of thiobarbituric acid reactive species (TBARS) was determined by using an extinction coefficient of $1.56 \times 10^{5} \mathrm{M}^{-1} \cdot \mathrm{cm}^{-1}$. Results were expressed as nmoles of MDA formed per $\mathrm{mg}$ of total protein.

\subsubsection{Reduced Glutathione (GSH) Determination} GSH concentration was estimated in lungs tissues according to the method described by Beutler et al, 1975 [36]. Briefly, the proteins of the samples were precipitated by adding precipitating solution (1.67\% metaphosphoric acid, $0.2 \%$ EDTA, 30\% NaCl). After centrifugation for $10 \mathrm{~min}, 8 \mathrm{ml}$ phosphate solution $(0.3 \mathrm{M})$ was added to $2 \mathrm{ml}$ of supernatant. After addition of DTNB to the reaction mixture absorbance was recorded at $412 \mathrm{~nm}$. Glutathione concentration was expressed as $\mu \mathrm{M} \mathrm{GSH} / \mathrm{mg}$ protein.

\subsubsection{Glutathione Reductase (GR) Estimation}

GR activity was assayed by the method described previously [37]. The assay mixture containing $0.2 \mathrm{M}$ potassium phosphate buffer ( $\mathrm{pH} 7.0), 2 \mathrm{mM}$ nicotinamide adenine dinucleotide phosphate (NADPH) and $20 \mathrm{mM}$ oxidized glutathione was mixed with distilled water to make final volume of $3 \mathrm{ml}$. Enzyme preparation/sample $(0.1 \mathrm{ml})$ was added to initiate the reaction and activity absorbance was measured at $340 \mathrm{~nm}$ for one minute at 15 sec interval. GR activity was expressed as $\mathrm{mU} / \mathrm{min} / \mathrm{mg}$ protein.

\subsubsection{Catalase Estimation}

Catalase activity was assayed by the method of Sinha et al. [38]. Briefly, the assay mixture consisted of $1.96 \mathrm{ml}$ phosphate buffer $(0.01 \mathrm{M}, \mathrm{pH} 7.0), 1.0 \mathrm{ml}$ hydrogen peroxide $(0.2 \mathrm{M})$ and $0.04 \mathrm{ml}$ phenazine methosulfate (PMS) $(10 \%)$ in a final volume of $3.0 \mathrm{ml}$. About $2 \mathrm{ml}$ dichromate acetic acid reagent was added in $1 \mathrm{ml}$ of reaction mixture, boiled for $10 \mathrm{~min}$, and was cooled. Absorbance of the supernatants was recorded at $570 \mathrm{~nm}$.

\subsection{Statistical Analysis}

The experiment results were expressed as mean $\pm \mathrm{SD}$ of three replicates. Student's paired t-test was used for analyzing the data. A value of $\mathrm{p}<0.05$ was considered as statistically significant.

\section{Results}

\subsection{Total and Differential Cell Counts in BALF}

Preparation of the microscope slide smear technique yielded well-preserved cell morphology. The total numbers of BALF cells were found increased in radiation exposed mice to controls. Differential cell counts in control group revealed an average proportion of $72.3 \% \pm$ $2.7 \%$ macrophages, $18.0 \% \pm 2.2 \%$ lymphocytes, $8.0 \% \pm$ $2.3 \%$ neutrophils. However, BALF collected from irradiated mice expressed increased percentage of neutrophils (Table 1). The increased number of neutrophils in BALF $(16 \%)$ was found to be decreased $(9 \%)$ in G-002M pretreated irradiated group. The radiation mediated increased number of total cell counts, macrophages and lymphocytes in BALF were also significantly countered 
Table 1. Total number of cells in BALF of experimental mice.

\begin{tabular}{|c|c|c|c|c|c|}
\hline S. No & Experimental Groups $(n=6)$ & Total cells in BALF $/\left(\mathrm{mm}^{3}\right)$ & Macrophages/(mm $\left.{ }^{3}\right)$ & Lyphocytes/(mm $\left.{ }^{3}\right)$ & $\begin{array}{l}\text { Neutrophils/ } \\
\left(\mathrm{mm}^{3}\right)\end{array}$ \\
\hline 1. & Control & $500 \pm 35$ & $360 \pm 15$ & $90 \pm 10$ & $40 \pm 8$ \\
\hline 2. & Radiation (7 Gy) & $1440 \pm 62^{\mathrm{a}^{* *}}$ & $918 \pm 32^{\mathrm{a}^{* *}}$ & $320 \pm 25^{a^{* *}}$ & $230 \pm 15^{\mathbf{a}^{* *}}$ \\
\hline 3. & G-002M + Radiation & $710 \pm 46^{\mathrm{b} * *}$ & $524 \pm 37^{\mathbf{b *}}$ & $100 \pm 12^{\mathbf{b}^{* *}}$ & $70 \pm 12^{\mathbf{b}^{* *}}$ \\
\hline
\end{tabular}

Values are mean \pm SD of the cells obtained from BALF collected individually from all the groups of experimental animals. Levels of significance of the differences are indicated as $p$ values. Study was repeated in three different sets of mice having three animals in each set. ${ }^{a}$ Radiation only group compared with controls; ${ }^{\mathrm{b}} \mathrm{G}-002 \mathrm{M}+$ Radiation group compared with radiation only group. ${ }^{* *} \mathrm{p}<0.001$.

by our formulation (Table 1). The percentage of differential cell counts obtained from ADVIA 120 Hematology system had been found in consonance with the percentage of cells counted from smear slide preparations of BALF (Figure 1).

\subsection{Reactive Oxygen Species (ROS)/NO Generation in BALF Cells}

ROS generation was measured in the BALF cells by using flow cytometry. Histograms (Figures 2(G) and (H)) represent differential ROS and NO generation respectively in all the three studied groups (control, irradiated and $\mathrm{G}-002 \mathrm{M}$ pretreated). In radiation only group ROS generation was found significantly increased when compared with controls. G-002M pretreatment apparently countered ROS upregulation. DCF-DA and DAF-2DA fluorescence observed under fluorescence microscope represented radiation mediated increase in ROS (Figure 2(B)) and NO production (Figure 2(E)) in comparison to corresponding controls (Figures 2(A) and (D)). G-002M significantly countered formation of both ROS (Figure 2(C)) and NO (Figure 2(F)).

\subsection{Expression of Inducible Nitric Oxide Synthase (iNOS) in BALF Cells}

Immunolabeling of iNOS in BALF cells was conducted in controls, irradiated and G-002M pretreated irradiated animals. Radiation ( $7 \mathrm{~Gy}$, whole body) increased the expression of iNOS in BALF cells as evident from the Figure 3(D). BALF cells collected from mice pretreated with formulation prior to radiation demonstrated low intensity of iNOS immunostaining (Figure 3(F)). Cells were counterstained with DAPI (Figures 3(A), (C) and (E)) as a confirmatory indication for presence of nucleus.

\subsection{Histology of Lung Tissues}

Histopathological examination performed on $15^{\text {th }}$ day after 7 Gy radiation exposure led to significant changes in the lung architecture like alveolar edema, damage of the alveolar cell lining, destruction of the interalveolar septae, inflammation and infiltration of lymphocytes.
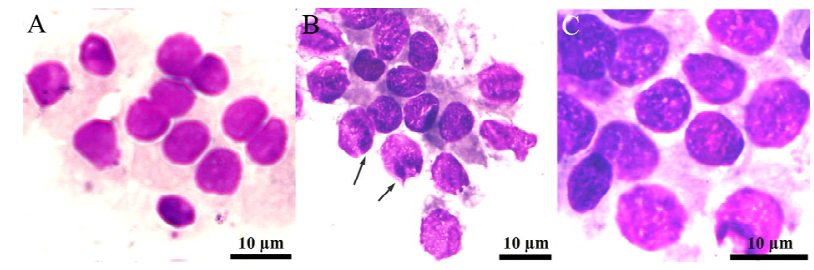

Figure 1. Images of BALF smears stained with MayGrünwald Giemsa stain and viewed at $1000 \times$ under trinocular microscope. (A) Control, showing macrophages; (B) BALF collected from irradiated mice showing increased number of neutrophils as evident by multilobulated nuclei (arrows) in most of the cells; (C) BALF collected from G-002M pretreated irradiated mice showing decreased neutrophils. Mice were dissected after 2 week of experimentation.
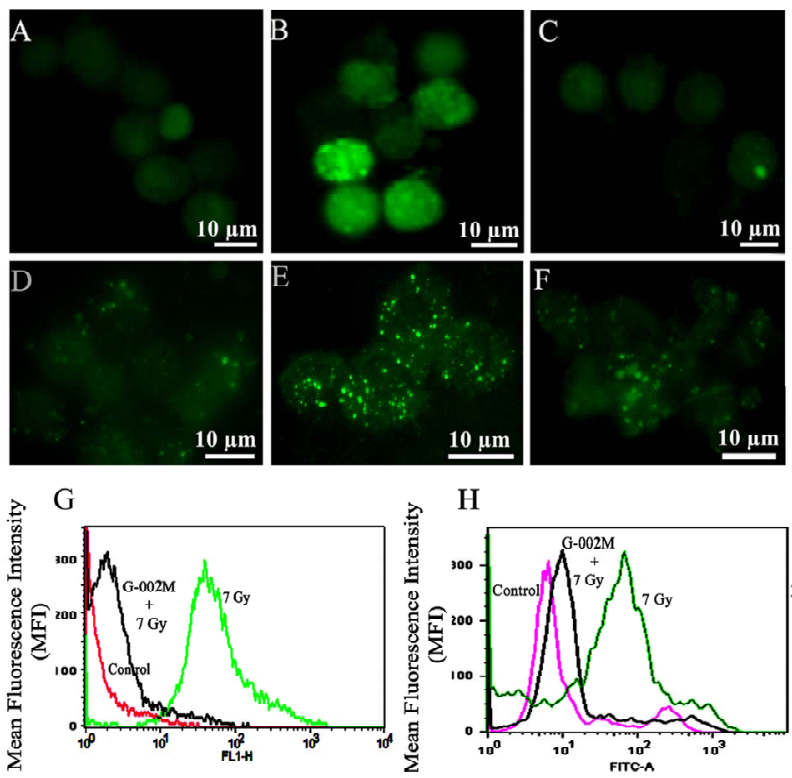

$\underline{10 \mu \mathrm{m}}$

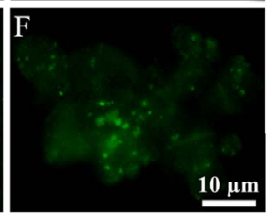

II

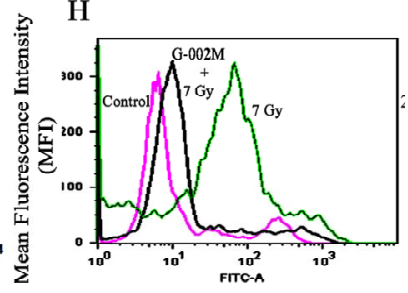

Figure 2. ROS/NO generation in the BALF cells. Images were viewed at $1000 \mathrm{X}$ under fluorescence microscope. ROS generation in (A) BALF cells from control animals; (B) 7Gy irradiated mice (C) Mice pretreated with G-002M formulation prior to radiation. Fluorescence intensity expressed the real time ROS generation in BALF cells. NO production observed in (D) BALF cells from control animals; (E) 7Gy irradiated mice; (F) Mice pretreated with G-002M formulation prior to radiation; (G) Histogram represents the ROS generation and $(\mathrm{H})$ NO production studied by flow cytometry. 
Acute pneumonitis was also visualized (Figure 4(B)). Administration of G-002M, $1 \mathrm{hr}$ prior to irradiation showed nonsignificant infiltration of lymphocytes in lung alveoli, minimal edematous changes and nil expression
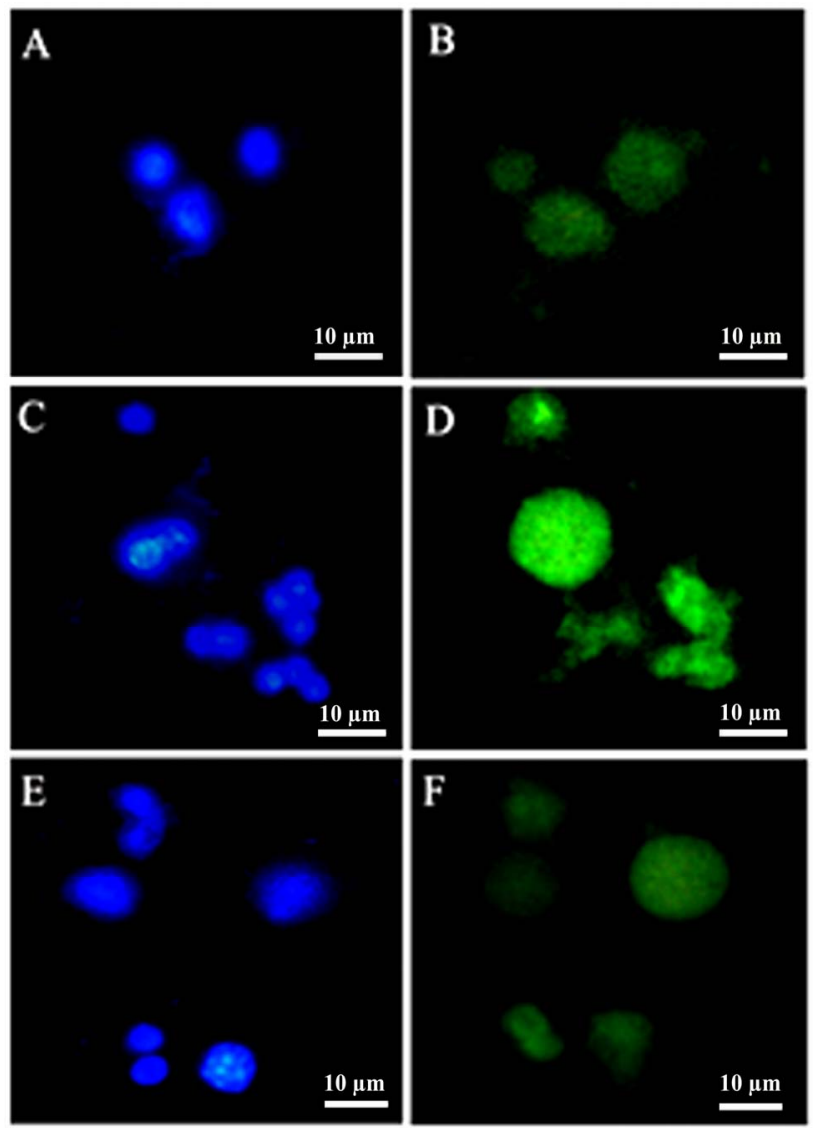

Figure 3. iNOS immunostaining in the BALF cells (A) Nucleus staining in controls (B) iNOS immunolabeling in the controls; (C) Nucleus stained with DAPI in irradiated groups of mice (D) iNOS immunolabeling in irradiated mice. (E) Nucleus staining in G-002M pretreated irradiated mice and (F) iNOS immunolabeling in G-002M pretreated mice. BALF cells were studied under fluorescence microscope at $1000 \times$. of acute pneumonitis (Figure 4(C)).

\subsection{Immunohistochemical Detection of iNOS}

Effect of ionizing radiation on expression of iNOS was explored in lung sections by immunohistochemistry. Advanced parenchymal fibrosis imparting a honeycomb architectural distortion of the lung tissue was observed in irradiated mice along with increased immunolabeling of iNOS. Lung architecture was found to be restored in the mice pretreated with G-002M before radiation exposure with less intense iNOS immunostaining in lung sections (Figure 5). Infilterated cells were seen in the air spaces, (Figure 5(D)) which were not observed in the G-002M pretreated groups (Figures 5(F)). Figure 5(G) shows the increased expression of iNOS in the irradiated groups which was found less in the G-002M pretreated groups. The expression of iNOS was not found to be detectable in the control group.

\subsection{Lung Permeability and Lung Cytotoxicity}

Lung permeability and damage was assessed by estimateing total protein and phospholipids content in BALF. For estimation of lung cytotoxicity, LDH activity was measured in BALF. Radiation exposed animals showed about 2 and 4 folds increase in phospholipids $(p<0.001)$ and protein contents $(p<0.001)$ respectively as compared to controls (Figures 6(A) and (B)). Lung cytotoxicity in the same group of mice, as evident by LDH activity (Figure 6(A)) was also found extensively increased (6 folds, $p<$ $0.001)$. Pretreatment of G-002M formulation resulted in decreased lung damage expressed by very low amount of protein, LDH and phospholipids content in BALF (Figure 6).

\subsection{Biochemical Studies in Lung Homogenates}

Glutathione reductase (GR), GSH and catalase along with lipid peroxidation (LPX) were measured in lung

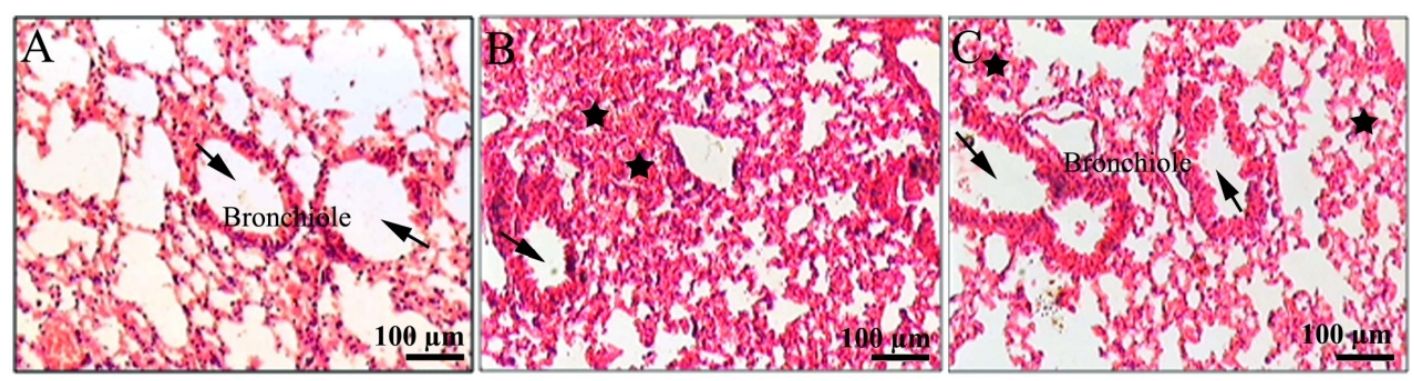

Figure 4. Histological examination of the lungs of mice of different treatment groups: (A) Lungs of controls had not expressed any pathological changes. Bronchiole with large air spaces (arrows) shown (B) lung from irradiated mice showing edema (black solid stars), infiltration of inflammatory cells, and reduced air spaces (arrow) (C) lung from G003M pretreated irradiated mice showing less edematous changes (black solid stars), nil infiltration of cells and bronchiole with large air spaces (arrows) as compared to irradiated group. 


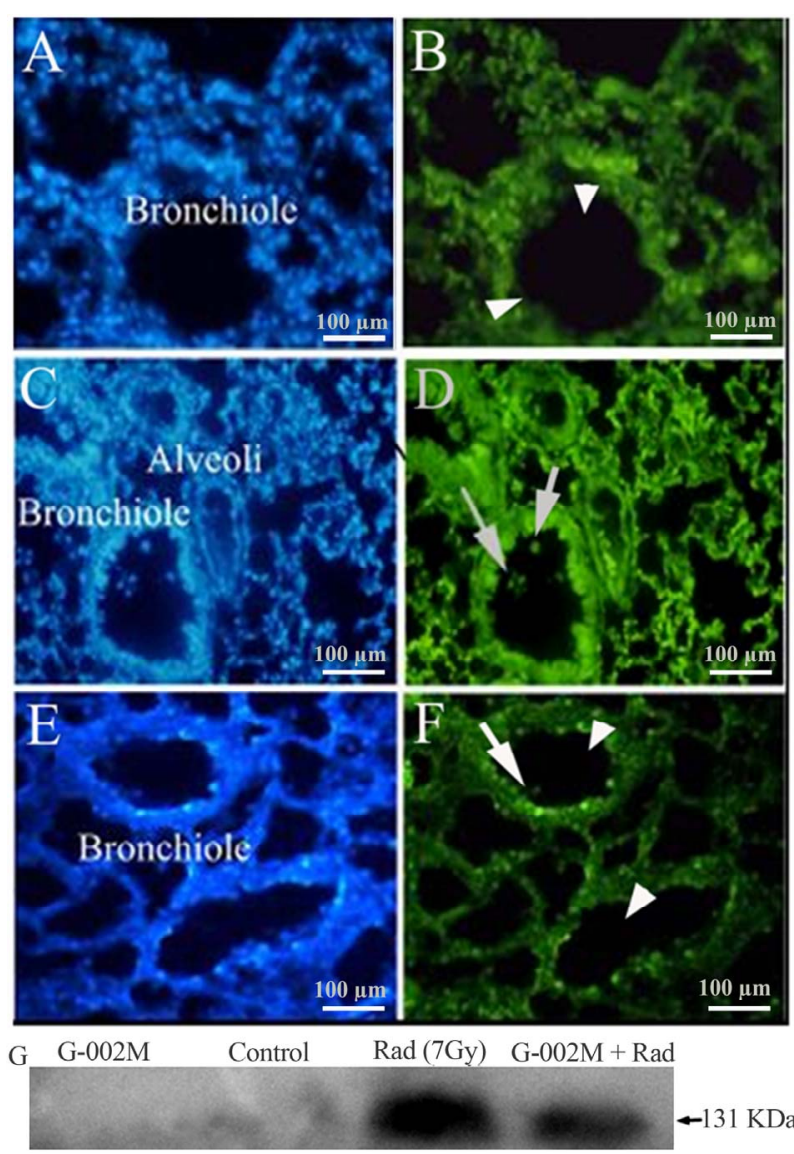

Figure 5. Images showing iNOS immunostaining in lung tissue sections (A) Nucleus (DAPI) staining in controls, (B) iNOS immunostaining in the controls showing bronchiole having large air spaces (arrowheads); (C) Nucleus stained with DAPI in irradiated groups of mice (D) iNOS immunostaining in the irradiated groups of mice showing intense iNOS expression (fluorescence) and infiltration of cells (arrows); (E) DAPI staining in the lung section of G-002M pretreated irradiated group (F) iNOS immunostaining in the G-002M pretreated irradiated group showing decreased iNOS expression (fluorescence), bronchioles with large air spaces (arrowheads) showing negligible infiltration of cells (arrow). Paraffin sections of lung tissue were stained with iNOS antibody and FITC coupled secondary antibody and observed under fluorescence microscope; (G) Western Blotting of iNOS in control, irradiated and G-002M pretreated group.

homogenates of irradiated mice, mice pretreated with G-002M and exposed to radiation, G-002M only, vehicle and untreated control group. GSH and catalase enzyme activities (Figures 7(A) and (B)) found decreased in the lung homogenates of irradiated mice (17.45 $\mu \mathrm{M} / \mathrm{mg}$ protein and $2.66 \mathrm{U} / \mathrm{mg}$ protein respectively), were restored in the homogenates of G-002M pretreated mice $(27.89 \mu \mathrm{M} / \mathrm{mg}$ protein and $3.32 \mathrm{U} / \mathrm{mg}$ protein respectively). Radiation enhanced peroxidation of lipids, though marginally $(0.231 \mathrm{nM}$ MDA $\times 1000 / \mathrm{mg}$ protein), was found decreased by G-002M (0.209 nM
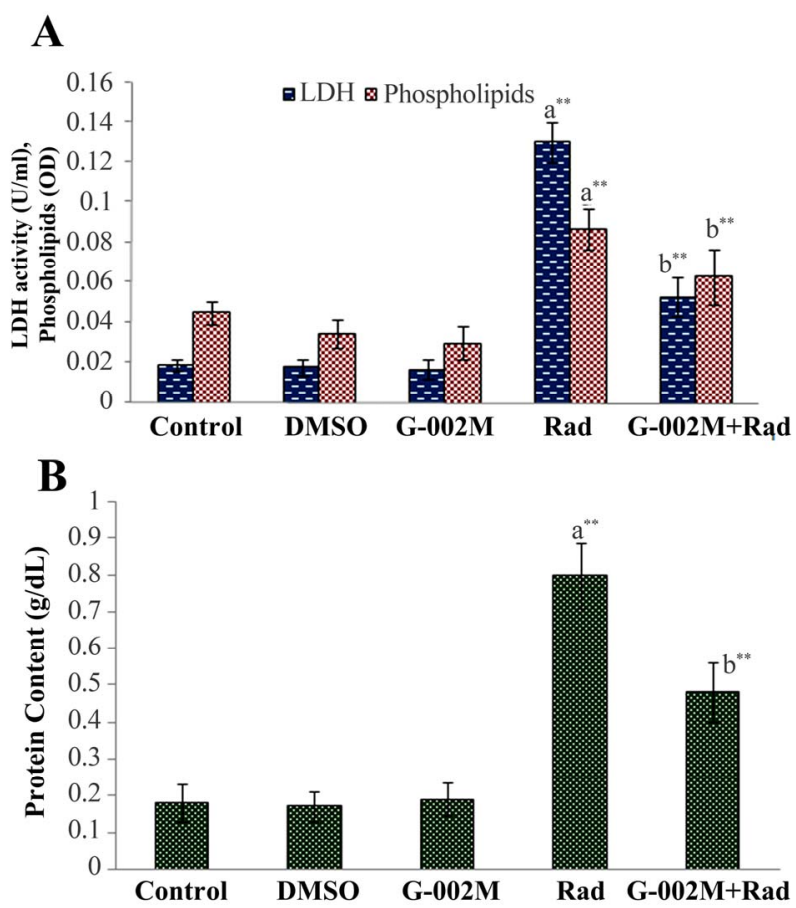

Figure 6. (A) Effect of G-002M on radiation induced alteration in LDH and phospholipids content in BALF of mice exposed to 7Gy whole body irradiation. Mice were sacrificed and lungs were lavaged 5 times with buffered saline. For LDH estimation samples were incubated with sodium pyruvate and the reaction was initiated by addition of NADH. Samples were measured at $340 \mathrm{~nm}$ for $15 \mathrm{sec}$ intervals. Phospholipids content was measured by recording absorbance at $470 \mathrm{~nm}$ against a blank without BALF. Study was repeated in three different sets of mice having three animals in each group; (B) Effect of G-002M on radiation induced alteration in total protein content in BALF of mice exposed to 7 Gy whole body irradiation. Mice were sacrificed after 2 weeks of experimentation and and lungs were lavaged 5 times with buffered saline. After centrifugation, BALF was collected for total protein estimation. Samples were incubated with Bradford reagent for $5 \mathrm{~min}$ at room temperature and absorbance was recorded at $595 \mathrm{~nm}$. Protein concentration was calculated by standard curve prepared by using different concentrations of BSA. ${ }^{\text {a }}$ Radiation only group compared with controls, ${ }^{b}$ G-002M + Radiation group compared with radiation only group. ${ }^{* *} \mathrm{p}<\mathbf{0 . 0 0 1}$.

MDA $\times 1000 / \mathrm{mg}$ protein) and values were corresponding to controls (Figure 7(C)). GR activity, which got declined in irradiated group (15.03 $\mathrm{mU} / \mathrm{min} / \mathrm{mg}$ protein), was found enhanced by G-002M pretreatment (17.04 $\mathrm{mU} / \mathrm{min} / \mathrm{mg}$ protein), but the difference was marginal when compared to control group of mice $(25.60 \mathrm{mU} /$ mins/mg protein). Values retrieved from the vehicle and drug only groups were almost parallel to controls (Figure 7).

\section{Discussion}

Radiation exposure may deregulate biological system 


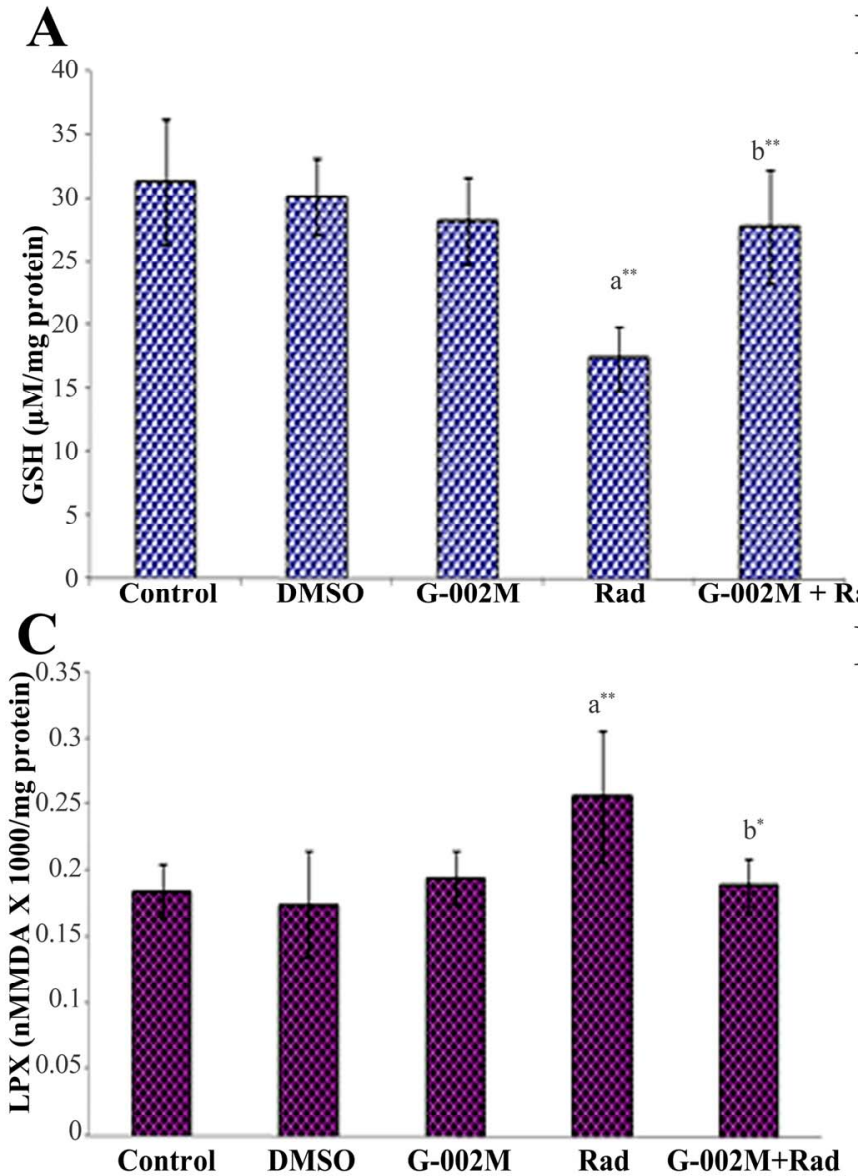

B
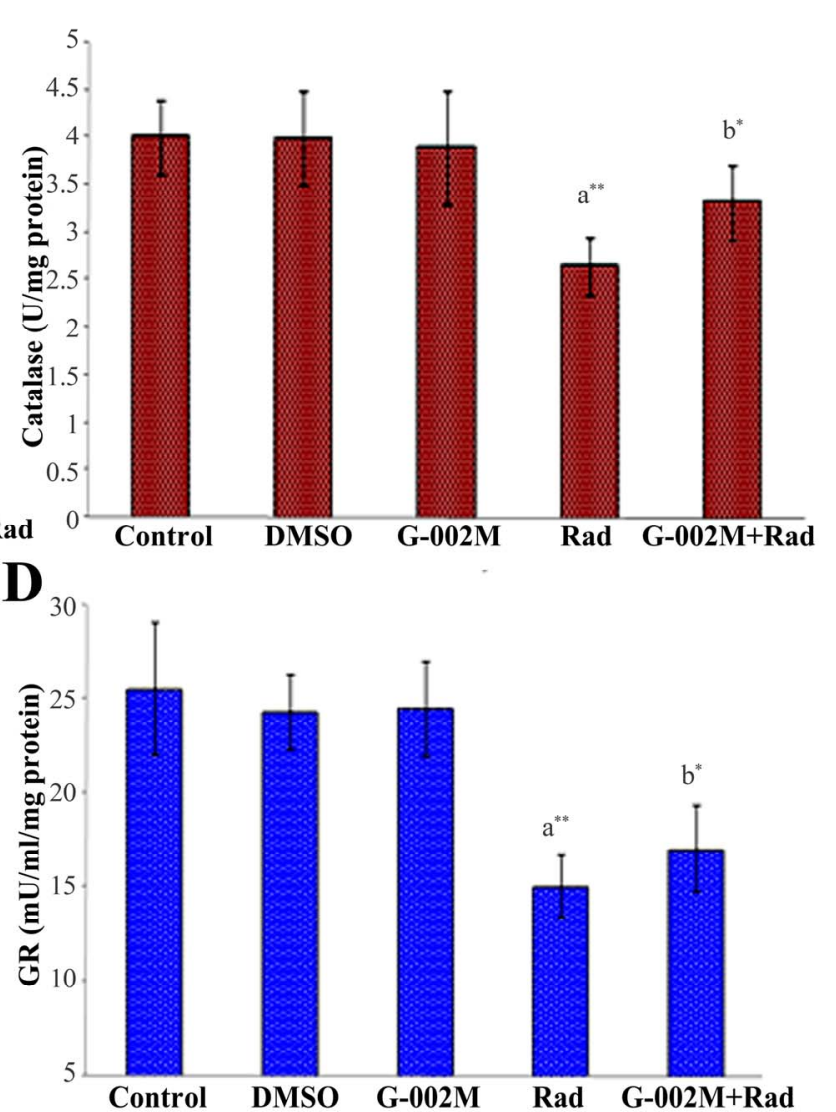

Figure 7. (A) Effect of G-002M on radiation induced alteration in GSH of lungs of mice exposed to 7 Gy whole body irradiation. Samples absorbance was recorded at $412 \mathrm{~nm}$. Glutathione concentration is expressed as $\mu \mathrm{M}$ GSH$/ \mathrm{mg}$ protein; (B) Effect of G-002M on radiation induced alteration in catalase activity of lungs of mice exposed to 7 Gy whole body irradiation. Supernatants of the lung homogenates were added to the assay mixture consisted of phosphate buffer and hydrogen peroxide, mixed with dichromate acetic acid reagent. Absorbance of the supernatants was recorded at $570 \mathrm{~nm}$; (C) Effect of G-002M on radiation induced alteration in lipid peroxidation of lungs of mice exposed to $7 \mathrm{~Gy}$ whole body irradiation. Lung homogenates from different treated groups of mice were mixed with TBA-TCA and boiled at $95^{\circ} \mathrm{C}$. Absorbance of the supernatants was recorded at $535 \mathrm{~nm}$. Results are expressed as nmoles of MDA formed per $\mathrm{mg}$ of protein; (D) Effect of G-002M on radiation induced alteration in GR activity of lungs of mice exposed to $7 \mathrm{~Gy}$ whole body irradiation. The assay mixture containing 0.2 M potassium phosphate buffer, $2 \mathrm{mM}$ nicotinamide adenine dinucleotide phosphate (NADPH) and 20 mM oxidized glutathione was mixed with distilled water and the reaction was initiated by addition of samples. Absorbance was measured at $340 \mathrm{~nm}$ for one minute at $15 \mathrm{sec}$ interval. GR activity is expressed as $\mathrm{mU} / \mathrm{min} / \mathrm{mg}$ protein. Study was repeated in three different sets of mice having three animals in each group. ${ }^{a}$ Radiation only group compared with controls, ${ }^{b} \mathrm{G}-002 \mathrm{M}+\mathrm{Radiation}$ group compared with radiation only group. ${ }^{* *} \mathrm{p}<0.001,{ }^{*} \mathrm{p}<0.01$.

also by hydrolysis of water in the cellular milieu thereby, generating reactive oxygen species, which initiate chemical peroxidative processes and affect the functionality of biomolecules [39]. Radiation induced free radical generation leads to oxidative stress which further results into nitrosative stress mediated by a chain of reactions involving reactive nitrogen species (RNS) mainly nitric oxide (NO) and peroxynitrite (ONOO-) [40]. Radiation induced damage to normal tissues can be averted by the use of safe prophylactic agents [41]. Development of radioprotector is an area of great significance due to its possible applications against unplanned/planned radia- tion exposures [41]. Enormous research and developmental efforts have been witnessed worldwide to develop safe radioprotectors to guard normal cells against radiotherapy, radiation explosions related rescue missions and space explorations. However, only a single compound, WR-2721, has so far received US FDA approval. Number of the investigations into radioprotector development have shown that the potential use of plants and their products can minimize the radiation mediated tissue damages $[24,42,43]$ with minimal toxic effects. $P$. hexandrum, a high altitude plant, has been in use under traditional medicine practice against rheumatism, plague, 
allergic and inflammatory conditions of the skin and various other types of cancers. Our studies with this plant have documented its use as a potent radioprotector against lethal doses of radiation in in-vitro, in-vivo, ex-vivo model systems $[22,44]$. Studies on P. hexandrum utilizeing semipurified fractions have proved its potent radioprotective effect against lethal and supralethal doses of radiation in rodents $[20,22,44]$. Recently, our group has reported the radioprotective properties of purified fractions of $P$. hexandrum [23]. The present study has been aimed to explore the mechanism by which our formulation leads to repair the radiation inflicted damage in the pulmonary system.

In the current study, degree of radiation induced pulmonary damage and its modification by G-002M was performed by the analysis of BALF using well reported parameters [45]. Scoring of neutrophils, important for marking inflammatory response in bronchoalveolar region, was among other markers evaluated currently. Studies on cellular enzyme lactate dehydrogenase (LDH), protein and phospholipids content and smear preparation for quantitation of total and differential cell counts in BALF (Table 1) have supported the evaluation on lung tissue damage and its recovery by G-002M.

Nitric oxide readily diffuses across the cells and is considered an important molecule in cellular signaling. Reactive nitrite species (nitric oxide) quenching potential of $P$. hexandrum has been described by Sagar et al. [46]. There are several reports suggesting increased nitric oxide synthase during radiation-induced oxidative stress [3], and some researchers have reported the role of nitric oxide in the pathogenesis of the inflammatory response in radiation enteritis [47]. Giannopoulou et al. [48] reported that amifostine exhibits antiangiogenesis activity by reducing the levels of nitric oxide; authors expressed that reduction in the levels of nitric oxide reduces the radiation mediated inflammatory responses. Earlier studies have also reported radiation mediated iNOS induction, as a major factor in inflicting lung injuries and nitrotyrosine formation may participate in the NO-induced pathogenesis [3]. Since iNOS is the major isoform related to NO production and RNS generation after radiation exposure, its expression was explored in mice BALF cells and in the lungs during current study. G-002M pretreatment exhibited considerable reduction in the iNOS expression. An increase of LDH levels in BALF after radiation exposure appeared to be associated with increased number of macrophages and neutrophils in lavage fluid (Figure 1). Pretreatment of G-002M formulation prior to radiation exposure resulted in decreased lung permeability and tissue damage as evident by low amount of protein and phospholipids in BALF and decreased LDH activity (Figure 6).

Oxidative stress is also known to be mitigated by the activation of several functionally interrelated antioxidant enzymes such as catalase, peroxidise and glutathione reductase $[49,50]$. These enzymes enhance acclimatisation mechanisms to scavenge the toxic free radicals of oxygen produced under stress condition. Oxidative stress accompanied by the synthesis of hydrogen peroxide is normally detoxified by catalase activity [51]. Radiation is known to downregulate the endogenous antioxidant enzymes (GSH, GR, catalase). These enzymes were found significantly upregulated by prophylactic administration of our P. hexandrum formulation (G-002M) in lethally irradiated mice confirming the scavenging of ROS/NO formation. Though G-002M pretreatment exhibited considerable restoration of GSH and catalase enzyme activeties (Figures 5(A) and (B) respectively) however, GR enzyme activity was found only marginally increased.

As well documented in other studies and confirmed by our studies too, support to immune system [22], hematopoietic system [21,46] and cellular DNA [21,22] by semipurified and purified formulations of $P$. hexandrum, is predominantly attributed to their free radical scavenging property, reduced lipid peroxidation [44], transient metal-chelation [21] and protection to endogenous defense enzymes and to cellular macromolecules [44]. The current study also demonstrates the possible involvement of $P$. hexandrum formulation $(\mathrm{G}-002 \mathrm{M})$ in modulation of radiation associated iNOS mediated RNS formation which ultimately resulted into the reduced damage of the lungs of irradiated mice. This drug with numerable radioprotective properties may be studied further to reveal its potential against radiation mediated respiratory syndromes in humans.

\section{Acknowledgements}

Authors are grateful to Defence Research Development and Organization (DRDO) for grant assistance. The assistance rendered by Mrs. Namita Kalra for flow cytometry measurement and Ms. Neetu Singh for support in histological studies is highly appreciated.

\section{REFERENCES}

[1] J. C. Lee, P. A. Kinniry, E. Arguiri, M. Serota, S. Kanterakis, S. Chatterjee, et al., "Dietary Curcumin Increases Antioxidant Defenses in Lung, Ameliorates Radiation-Induced Pulmonary Fibrosis, and Improves Survival in Mice," Radiation Research, Vol. 173, No. 5, 2010, pp. 590-601. doi:10.1667/RR1522.1

[2] V. Mehta, "Radiation Pneumonitis and Pulmonary Fibrosis in Non-Small-Cell Lung Cancer: Pulmonary Function, Prediction, and Prevention," International Journal of Radiation Oncology Biology Physics, Vol. 63, No. 1, 2005, pp. 5-24. doi:10.1016/j.ijrobp.2005.03.047

[3] C. Tsuji, Shioya, Y. Hirota, N. Fukuyama, D. Kurita, T. Tanigaki, et al., "Increased Production of Nitrotyrosine in 
Lung Tissue of Rats with Radiation-induced Acute Lung Injury," American Journal of Physiology Lung Cellular and Molecular Physiology, Vol. 278, No. 4, 2000, pp. 719-725.

[4] P. G. Tsoutsou and M. I. Koukourakis, "Radiation Pneumonitis and Fibrosis: Mechanisms Underlying its Pathogenesis and Implications for Future Research," International Journal of Radiation Oncology Biology Physics, Vol. 66, No. 5, 2006, pp. 1281-1293.

doi:10.1016/j.ijrobp.2006.08.058

[5] A. Giaid, S. M. Lehnert, B. Chehayeb, D. Chehayeb, I. Kaplan and G. Shenouda, "Inducible Nitric Oxide Synthase and Nitrotyrosine in Mice with Radiation-Induced Lung Damage," American Journal of Clinical Oncology, Vol. 26, No. 4, 2003, pp. 67-72. doi:10.1097/01.COC.0000077940.05196.86

[6] J. A. Royall, N. W. Kooy and J. S. Beckman, "Nitric Oxide-Related Oxidants in Acute Lung Injury," New Horizons, Vol. 3, No. 1, 1995, pp. 113-122.

[7] Y. Nozaki, Y. Hasegawa, A. Takeuchi, Z. H. Fan, K. I. Isobe, I. Nakashima, et al., "Nitric Oxide as an Inflammatory Mediator of Radiation Pneumonitis in Rats," American Journal of Physiology Lung Cellular and Molecular Physiology, Vol. 272, No. 4, 1997, pp. 651-658.

[8] R. Saini, S. Patel, R. Saluja, A. A Sahasrabuddhe, M. P. Singh, S. Habib, V. K. Bajpai, et al., "Nitric Oxide Synthase Localization in the Rat Neutrophils: Immunocytochemical, Molecular and Biochemical Studies," Journal of Leukocyte Biology, Vol. 79, No. 3, 2006, pp. 519-528. doi:10.1189/jlb.0605320

[9] K. J. Park, Y. T. Oh, W. J. Kil, W. Park, S. H. Kang and M. Chun, "Bronchoalveolar Lavage Findings of Radiation Induced Lung Damage in Rats," Journal of Radiation Research, Vol. 50, No. 3, 2009, pp. 177-182. doi:10.1269/jrr.08089

[10] U. Costabel and J. Guzman, "Bronchoalveolar Lavage in Intestinal Lung Disease," Current Opinion in Pulmonary Medicine. Vol. 7, No. 5, 2001, pp. 255-261.

[11] J. Bousquet, P. Chanez, J. Y. Lacoste, G. Barnéon, N. Ghavanian, I. Enander, et al., "Eosinophilic Inflammation in Asthma," New England Journal of Medicine, Vol. 323, No. 15,1990 , pp. 1033-1039. doi:10.1056/NEJM199010113231505

[12] J. Y. Lacoste, J. Bousquet, P. Chanez, T. Van Vyve, J. Simony-Lafontaine, N. Lequeu, et al., "Eosinophilic and Neutrophilic Inflammation in Asthma, Chronic Bronchitis, and Chronic Obstructive Pulmonary Disease," Journal of Allergy and Clinical Immunology, Vol. 92, No. 4, 1993, pp. 537-548. doi:10.1016/0091-6749(93)90078-T

[13] D. A. Campbell, L. W. Poulter and R. M. du Bois, "Immunocompetent Cells in Bronchoalveolar Lavage Reflect the Cell Populations Intransbronchial Biopsies in Pulmonary Sarcoidosis," American Review of Respiratory Disease, Vol. 132, No. 6, 1985, pp. 1300-1306.

[14] P. J. Haslam, C. W. G. Turton, B. Heard, A. Lukoszek, J. V. Collins, A. J. Salsbury, et al., "Bronchoalveolar Lavage in Pulmonary Fibrosis: Comparison of Cells Obtained with Lung Biopsy and Clinical Features," Thorax, Vol. 35, No. 1, 1980, pp. 9-18. doi:10.1136/thx.35.1.9

[15] G. W. Hunninghake, O. Kawanami, V. J. Ferrans, R. C. Jr Young, W. C. Roberts and R. G. Crystal, "Characterization of Inflammatory and Immune Effector Cells in the Lung Parenchyma of Patients with Interstitial Lung Disease," American Review of Respiratory Disease, Vol. 123, No. 4, 1981, pp. 407-412.

[16] I. L. Paradis, J. H. Dauber and B. S. Rabin, "Lymphocyte Phenotypes in bronchoalveolar Lavage and Lung Tissue in Sarcoidosis and Idiopathic Pulmonary Fibrosis," American Review of Respiratory Disease, Vol. 133, No. 5, 1986, pp. 855-860.

[17] G. Semenzato, M. Chilosi, E. Ossi, L. Trentin, G. Pizzolo, A. Cipriani, et al., "Bronchoalveolar Lavage and Lung histology: Comparative Analysis of Inflammatory and Immunocompetent Cells in Patients with Sarcoidosis and Hypersensitivity Pneumonitis," American Review of Respiratory Disease, Vol. 132, No. 2, 1985, pp. 400-404.

[18] M. B. Gotway, "Interstitial lung Diseases: Imaging Evaluation," Applied radiology, Vol. 29, No. 9, 2000, pp. 31-46. doi:10.1016/S0160-9963(00)80215-0

[19] M. D. Rossman, J. A. Kern, J. A. Elias, M. R. Cullen, P. E. Epstein and O. P. Preuss, "Proliferative Response of Broncho Alveolar Lymphocytes to Beryllium," Annals of Internal Medicine, Vol. 108, No. 5, 1988, pp. 687-693. doi:10.7326/0003-4819-108-5-687

[20] M. Lata, J. Prasad, S. Singh, R. Kumar, L. Singh, P. Chaudhary, et al., "Whole Body Protection against Lethal Ionizing Radiation in Mice by REC-2001: A Semi-Purified Fraction of Podophyllum hexandrum," Phytomedicine, Vol. 16, No. 1, 2009, pp. 47-55. doi:10.1016/j.phymed.2007.04.010

[21] M. L. Gupta, V. Gupta, S. K. Shukla, S. Verma, S. Sankhwar, A. Dutta, et al., "Inhibition in Radiation Mediated Cellular Toxicity by Minimizing Free Radical Flux: One of the Possible Mechanisms of Biological Protection against Lethal Ionizing Radiation by a Subfraction of Podophyllum hexandrum," Cellular and Molecular Biology, Vol. 56, Suppl. OL1341-9, 2010. doi:10.1170/153

[22] S. Sankhwar, M. L. Gupta, V. Gupta, S. Verma, K. A. Suri, M. Devi, et al., "Podophyllum hexandrum Mediated Survival Protection and Restoration of Other Cellular Injuries in Lethally Irradiated Mice," Evidence Based Complementary and Alternative Medicine, 2011, Article ID: 175140. doi: $10.1093 /$ ecam/nep061

[23] A. Dutta, S. Verma, S. Sankhwar, S.J. Flora and M. L. Gupta, "Bioavailability, Antioxidant and Non Toxic Properties of a Radioprotective Formulation Prepared from Isolated Compounds of Podophyllum hexandrum: A Study in Mouse Model," Cellular and Molecular Biology, Vol. 58,2012

[24] S. K. Shukla and M. L. Gupta, "Approach Towards Development of a Radioprotector Using Herbal Source Against Lethal Irradiation," International Research Journal of Plant Science, Vol. 1, No. 1, 2010, pp. 118-125.

[25] A. Kawana, S. Shioya, H. Katoh, C. Tsuji, M. Tsuda and Y. Ohta, "Expression of Intercellular Adhesion Molecule-1 and Lymphocyte Function-Associated Antigen-1 on Alveolar Macrophages in the Acute Stage of Radia- 
tion-Induced Lung Injury in Rats," Radiation Research, Vol. 147, No. 4, 1997, pp. 431-436.

doi: $10.2307 / 3579499$

[26] S. Shioya, C. Tsuji, D. Kurita, H. Katoh, M. Tsuda, M. Haida, et al., "Early Damage to Lung Tissue after Irradiation Detected by the Magnetic Resonance T2 Relaxation Time," Radiation Research, Vol. 148, No. 4, 1997, pp. 359-364. doi: $10.2307 / 3579521$

[27] Q. Zhang, Y. Kusaka, Q. Zhang, L. He, Z. Zhang and K. Sato, "Dynamic Changes of Constituents in Bronchoalveolar Lavage Fluid in Experimental Silicotic Rats," Industrial Health, Vol. 34, No. 4, 1996, pp. 379-388. doi:10.2486/indhealth.34.379

[28] M. Natiello, G. Kelley, J. Lamca, D. Zelmanovic, R. W. Chapman and J. E. Phillips, "Manual and Automated Leukocyte Differentiation in Bronchoalveolar Lavage Fluids from Rodent Models of Pulmonary Inflammation," Comparative Clinical Pathology, Vol. 18, No. 2, 2009, pp. 101-111. doi:10.1007/s00580-008-0772-9

[29] A.B. Thompson, H. Teschler, Y. M. Wang, N. Konietzko and U. Costabel, "Preparation of Bronchoalveolar Lavage Fluid with Microscope Slide Smears". European Respiratory Journal, Vol. 9, No. 3, 1996, pp. 603-608. doi:10.1183/09031936.96.09030603

[30] P. Sharma, S. A. V. Raghavan, R. Saini, and M. Dikshit, "Functional Role of Ascorbic Acid in the Regulation of Free Radical Generation and Phagocytosis by Polymorphonuclear Leukocytes: A No-Mediated Effect," Journal of Leukocyte Biology, Vol. 75, No. 6, 2004, pp. 10701078. doi:10.1189/jlb.0903415

[31] B. Vojtesek, J. Bartek, C.A. Midgley and D. P. Lane, “An Immunochemical Analysis of the Human Nuclear Phosphoprotein P53. New Monoclonal Antibodies and Epitope Mapping Using Recombinant P53," Journal of Immunological Methods, Vol. 151, No. 1-2, 1992, pp. 237-244. doi:10.1016/0022-1759(92)90122-A

[32] P. Seth, R. Kumari, M. Dikshit and R. C. Srimal, "Modulation of Rat Peripheral Polymorphonuclear Leukocyte Response by Nitric Oxide and Arginine," Blood, Vol. 84, No. 8, 1994, pp. 2741-2748.

[33] M. Bradford, "A Rapid And Sensitive Method for the Quantitation of Microgram Quatities of Protein Utilizing the Principle of Protein-Dye Binding," Analytical Biochemistry, Vol. 72, No. 1-2, 1976, pp. 248-254. doi:10.1016/0003-2697(76)90527-3

[34] Y. Yoshida, E. Furuya and K. Tagawa, "A Direct Colorimetric Method for the Determination of Phospholipids with Dithiocyanatoiron Reagent," Journal of Biochemistry, Vol. 88, No. 2, 1980, pp. 463-468.

[35] J. A. Buege and S. D Aust, "Microsomal Lipid Peroxidation," Methods Enzymology, Vol. 52, 1978, pp. 302-310. doi:10.1016/S0076-6879(78)52032-6

[36] E. Beutler, "Reduced Glutathione-GSH, U: Beutler E. (Ur.) Red Cell Metabolism: A Manual of Biochemical Methods," Grane and Straton, New York, 1975.

[37] I. Carlberg and B. Mannervik, "Glutathione Reductase," Methods Enzymology, Vol. 113, 1985, pp. 484-490. doi:10.1016/S0076-6879(85)13062-4
[38] A. K. Sinha, "Colorimetric Assay of Catalase," Analytical Biochemistry, Vol. 47, No. 2, 1972, pp. 389-394.

[39] Y. Z. Fang, S. Yang and G. Wu, "Free Radicals, Antioxidants, and Nutrition," Nutrition Journal, Vol. 18, No. 10,2002 , pp. $872-879$. doi:10.1016/S0899-9007(02)00916-4

[40] M. Kirsch and H. de Groot, "Formation of Peroxynitrite from Reaction of Nitroxyl Anion with Molecular Oxygen," The Journal of Biological Chemistry, Vol. 277, No. 16, 2002, pp. 13379-13388. doi:10.1074/jbc.M108079200

[41] S. J. Hosseinimehr, "Trends in the Development of Radioprotective Agents," Drug Discovery Today, Vol. 12, No. 19-20, 2007, pp. 794-805. doi:10.1016/j.drudis.2007.07.017

[42] S. Verma, M. L. Gupta, A. Dutta, S. Sankhwar, S. K. Shukla and S. J. Flora, "Modulation of Ionizing Radiation Induced Oxidative Imbalance by Semi-Fractionated Extract of Piper Betle: An in Vitro and in Vivo Assessment," Oxidative Medicine and Cellular Longevity, Vol. 3, No. 1, 2010, pp. 44-52. doi:10.4161/oxim.3.1.10349

[43] D. P. Uma Devi, A. Ganasoundari, B. S. Rao and K. K. Srinivasan, "In Vivo Radioprotection by Ocimum Flavonoids: Survival of Mice," Radiation Research, Vol. 151, No. 1, 1999, pp. 74-78. doi:10.2307/3579750

[44] M. L. Gupta, S. Tyagi, S. J. Flora, P. K. Agrawala, P. Choudhary, S. C. Puri, et al., "Protective Efficacy of Semi Purified Fraction of High Altitude Podophyllum hexandrum Rhizomes in Lethally Irradiated Swiss Albino Mice," Cellular and Molecular Biology, Vol. 53, No. 5, 2007, pp. 29-41.

[45] H. Y. Reynolds, "Bronchoalveolar Lavage," American Review of Respiratory Disease, Vol. 135, No. 1, 1987, pp. 250-263.

[46] R. K. Sagar, R. Chawla, R. Arora, S. Singh, B. Krishna, R. K. Sharma, et al., "Protection of Hematopoietic System by Podophyllum hexandrum against Gamma RadiationInduced Damage," Planta Medica, Vol. 72, No. 2, 2006, pp. 114-120. doi:10.1055/s-2005-873148

[47] Y. Erbil, C. Dibekoglu, U. Turkoglu, E. Ademoglu, E. Berber, A. Kizir, et al., "Nitric Oxide and Radiation Enteritis," European Journal of Surgery, Vol. 164, No. 11 1998, pp. 863-868. doi:10.1080/110241598750005291

[48] E. Giannopoulou, P. Katsoris, D. Kardamakis and E. Papadimitriou, "Amifostine Inhibits Angiogenesis in Vivo," Journal of Pharmacology and Experimental Therapy, Vol. 304, No. 2, 2003, pp. 729-737. doi:10.1124/jpet.102.042838

[49] P. V. Limaye, N. Raghuram and S. Sivakami, "Oxidative Stress and Gene Expression of Antioxidant Enzymes in the Renal Cortex of Streptozotocin Induced Diabetic Rats," Molecular Cell Biochemistry, Vol. 243, No. 1-2, 2003, pp. 147-152.

[50] I. Zelen, P. Djurdjevic, S. Popovic, M. Stojanovic, V. Jakovljevic, S. Radivojevic, et al., "Antioxidant Enzymes Activities and Plasma Levels of Oxidative Stress Markers in B-Chronic Lymphocytic Leukemia Patients," Journal of Balkan Union of Oncology, Vol. 15, No. 2, 2010, pp. 330-336. 
[51] C. H. Foyer, H. Lopez-Delgado, J. F. Dat and I. M. Scott, "Hydrogen Peroxide- and Glutathione-Associated Mechanisms of Acclamatory Stress Tolerance and Signalling,"
Physiologia Plantarum, Vol. 100, No. 2, 1997, pp. 241254. doi:10.1111/j.1399-3054.1997.tb04780.x 